\title{
Avaliação macro e microscópica do trato digestório de frangos de corte alimentados com dieta contendo glicerina
}

\author{
Denise Cerqueira Sousa, Nadja Lamonye Alves Oliveira, Edna Teles dos Santos, \\ Leilane Rocha Barros Dourado, Guilherme José Bolzani de Campos Ferreira*
}

Universidade Federal do Piaui, Bom Jesus, PI, Brasil

Autor correspondente, e-mail: guilherme.ferreira@pq.cnpq.br

\begin{abstract}
Resumo
Avaliou-se a presença de alterações morfológicas no tubo digestório de frangos de corte alimentados com dieta contendo $7 \%$ de glicerina. Utilizou-se 16 animais, machos, da linhagem Cobb $500^{\oplus}$, distribuídos em delineamento inteiramente casualizado divido em dois tratamentos: animais alimentados com dieta sem glicerina e alimentados com dieta contendo $7 \%$ de glicerina. Foi observado que a adição de glicerina a $7 \%$ na dieta de frangos de corte leva a ocorrência significativa de infiltrados inflamatório no pro ventrículo, nos cecos e no cólon desses animais, macroscopicamente a adição de glicerina na dieta não ocasionou nenhuma diferença estatística, contudo essas alterações não ocasionaram diferença significativa no desempenho zootécnico desses animais. Conclui-se que o uso da glicerina na dieta pode ocasionar processos inflamatórios localizados, em função de sua característica alcoólica que degrada a barreira muco protetora e possui absorção passiva e expõe o epitélio mucótico a ação do suco gástrico, favorecendo assim o processo inflamatório da mucosa. No intestino grosso (cecos e cólon) a resposta inflamatória apresentou maior intensidade em função desses órgãos possuírem maior concentração de tecido linfático (nodular e difuso) e nesta porção o intestino realiza a reabsorção de líquidos competindo diretamente com a glicerina que é altamente higroscópica.
\end{abstract}

Palavras-chave: histopatologia, glicerol, infiltrado inflamatório

\section{Macro and microscopic evaluation of the digestive tract of broilers fed a diet containing glycerin}

\begin{abstract}
This study aimed to evaluate the presence of morphological changes in the digestive tract of broilers fed diets containing $7 \%$ glycerol. It was used 16 animals from male Cobb $500^{\circledast}$ line, distributed in a completely randomized design in two treatments: animals fed diet without glycerin and animals fed diets containing $7 \%$ glycerol. It was observed that the addition of glycerin at $7 \%$ in the diet of broilers promotes the occurrence of significant inflammatory infiltrates in the proventriculus, caecum and colon of such animals, macroscopically the addition of glycerin in the diet did not cause any significant difference, but these differences had no significant effect on zootechnical development of such animals. It is possible to conclude that the use of glycerin in the diet can cause localized inflammatory processes, due to its alcoholic feature that degrades the protective mucus barrier and it presents passive absorption and exposes the mucus epithelium to the gastric juice action, thus promoting the mucosa inflammatory process. In the large intestine (cecum and colon) the inflammatory response showed greater intensity as a function of these organs have higher lymphatic tissue (nodular and diffuse)concentration and at this portion the intestine performs the fluids reabsorption directly competing with glycerin which is highly hygroscopic.
\end{abstract}

Keywords: histopathology, glycerol, inflammatory infiltrate 


\section{Introdução}

A avicultura de corte desenvolve continuamente pesquisas que visam reduzir os custos de produção, considerando que a alimentação é o fator responsável por maior parte dos custos, para suprimir essa demanda, surge há busca por alimentos alternativos. A utilização de glicerina bruta oriunda da produção de biodiesel na alimentação de frangos de corte tem demonstrado bons resultados no desempenho desses animais, sendo uma boa estratégia de manejo alimentar, por ser de baixo custo e possuir alto valor energético, além de contribuir de forma sustentável para o destino desse subproduto, tendo em vista que este possui inúmeras impurezas e a quantidade gerada aumenta a cada ano, segundo os dados da Agência Nacional do Petróleo, Gás Natural e Combustivel através do seu Anuário Estatístico realizado em 2013. Arruda et al, (2007) relata que o glicerol é permitido como aditivo alimentar, considerado como atóxico quando usado dentro dos limites de recomendação. E essas vantagens tem despertado interesse de muitos pesquisadores (Cerrate et al., 2006; Guerra et al., 2011; Santos et al., 2013; Sousa et al., 2015a; Mandalawi et al., 2014), em relação a ação da glicerina no desempenho de frangos, com isso há vários estudos, no âmbito de verificar qual o percentual de inclusão ideal desse ingrediente na dieta, com o intuito de melhoria na produção desses animais. Contudo, não há estudos acerca da influência da glicerina bruta sobre as características morfofisiológicas do sistema digestórios desses animais.

- prévio conhecimento da morfofisiologia do trato digestório das aves é essencial na compreensão dos ganhos em desempenho e facilita a incorporação de novas estratégias alimentares que sejam viáveis economicamente. Entretanto, a preocupação não deve estar voltada somente para a eficiência financeira do sistema atual de produção, mas também com o bem estar desses animais, logo a avaliação morfológica do sistema digestório dos animais que consomem diferentes ingredientes deve ser realizada, visando contribuir de forma consciente com o desenvolvimento avícola. Sousa et al (2015) em seu trabalho, realizou uma completa descrição macro e microscópico do trato gastrointestinal de frangos de corte da linhagem Cobb 500.

Considerando que a presença de alterações no decorrer do trato digestório podem desencadear graves danos à sanidade avícola e em consequência causar prejuízos no setor, torna-se necessário conhecer a ação dos diferentes ingredientes que são incluídos na dieta desses animais.

Diante desse contexto, objetivou-se avaliar a presença de alterações morfológicas no tubo digestório de frangos de corte alimentados com dieta contendo $7 \%$ de glicerina.

\section{Material e métodos}

O experimento foi conduzido no setor de avicultura do Colégio Técnico de Bom Jesus, da Universidade Federal do Piauí, em Bom Jesus, Piauí, em galpão experimental. Foram utilizados 16 animais, machos da linhagem Cobb $500^{\circledR}$. Os animais foram distribuídos aleatoriamente em dois tratamentos, com quatro repetições, com 2 animais em cada boxe, em um Delineamento Inteiramente Casualizado (DIC), com dois tratamentos: animais alimentados com ração contendo $7 \%$ de inclusão de glicerina (grupo teste) e animais alimentados com ração sem inclusão de glicerina (grupo controle).

A composição da glicerina utilizada nas dietas experimentais encontra-se na tabela 01 e com base nos percentuais desse ingrediente calculou-se a composição percentual das rações experimentais do grupo teste.

Tabela 01. Composição nutricional, físico-química e energética da glicerina utilizada nas dietas de frangos de corte.

\begin{tabular}{|c|c|}
\hline Características & Resultado \\
\hline Cinzas sulfatadas $\%$ & 7,20 \\
\hline Cloro' $\%$ & 3,55 \\
\hline $\mathrm{NaCl}^{\prime} \%$ & 5,84 \\
\hline Residual metanol' \% & 0,003 \\
\hline Sódio’ \% & 2,29 \\
\hline Monoglicerídeos ${ }^{1} \%$ & 1,30 \\
\hline Glicerol' \% & 80,95 \\
\hline Umidade' \% & 10,60 \\
\hline Densidade a $20^{\circ} \mathrm{C}^{\prime} \mathrm{g} / \mathrm{ml}$ & 1,26 \\
\hline Acidez $\%$ & 0,90 \\
\hline $\mathrm{pH}^{1}$ & 6,20 \\
\hline Energia Bruta kcal/kg & 3774 \\
\hline Energia Metabolizável² kcal/kg & 3585 \\
\hline
\end{tabular}


As rações foram formuladas para atender as exigências nutricionais de frangos machos de desempenho regular, conforme os níveis nutricionais recomendados por Rostagno et al. (2011), as composições das rações nas diferentes fases estão apresentadas na tabela 02.

Tabela 2. Composição centesimal e níveis calculados dos nutrientes das dietas Controle (C), sem glicerina e dieta Teste (T) contendo $7 \%$ de glicerina nas fases estudadas para frangos de corte.

\begin{tabular}{|c|c|c|c|c|c|c|c|c|c|c|}
\hline \multirow{3}{*}{ Ingredientes (\%) } & \multicolumn{8}{|c|}{ Fases de criação } & & \\
\hline & \multicolumn{2}{|c|}{$1-7$} & \multicolumn{2}{|c|}{$8-21$} & \multicolumn{2}{|c|}{$22-33$} & \multicolumn{2}{|c|}{$34-42$} & \multicolumn{2}{|c|}{$43-46$} \\
\hline & C & $\mathbf{T}$ & C & $\mathrm{T}$ & C & $\mathbf{T}$ & C & $\mathbf{T}$ & C & $\mathbf{T}$ \\
\hline Milho & 55,14 & 46,70 & 62,12 & 53,51 & 64,49 & 56,03 & 68,53 & 60,07 & 70,41 & 61,83 \\
\hline Farelo de Soja & 37,90 & 39,38 & 32,45 & 33,98 & 30,01 & 31,50 & 26,68 & 28,17 & 24,74 & 26,25 \\
\hline Óleo de Soja & 2,03 & 2,05 & 1,36 & 1,46 & 1,98 & 2,01 & 1,83 & 1,85 & 2,23 & 2,35 \\
\hline Glicerina ADM & 0,00 & 7,00 & 0,00 & 7,00 & 0,00 & 7,00 & 0,00 & 7,00 & 0,00 & 7,00 \\
\hline Sal Comum & 0,51 & 0,11 & 0,48 & 0,08 & 0,45 & 0,05 & 0,44 & 0,04 & 0,43 & 0,03 \\
\hline DL-MetioninaMHA 84 & 0,42 & 0,43 & 0,33 & 0,34 & 0,27 & 0,28 & 0,24 & 0,25 & 0,20 & 0,21 \\
\hline L-Lisine 79 & 0,28 & 0,25 & 0,24 & 0,21 & 0,19 & 0,16 & 0,19 & 0,16 & 0,15 & 0,13 \\
\hline Cloreto de amônia & 0,00 & 0,36 & 0,00 & 0,36 & 0,00 & 0,36 & 0,00 & 0,36 & 0,00 & 0,36 \\
\hline Calcário Calcítico & 0,91 & 0,90 & 1,05 & 1,05 & 0,94 & 0,93 & 0,83 & 0,82 & 0,76 & 0,75 \\
\hline Inerte & 0,50 & 0,50 & 0,10 & 0,10 & 0,00 & 0,00 & 0,00 & 0,00 & 0,00 & 0,00 \\
\hline Fosfato Bicálcico & 1,91 & 1,92 & 1,50 & 1,50 & 1,24 & 1,25 & 1,02 & 1,03 & 0,88 & 0,89 \\
\hline Suplevitmin-nutron' & 0,40 & 0,40 & 0,40 & 0,40 & 0,40 & 0,40 & 0,20 & 0,20 & 0,20 & 0,20 \\
\hline \multicolumn{11}{|c|}{ Composição nutricional e energética } \\
\hline Potássio (\%) & 0,85 & 0,85 & 0,77 & 0,77 & 0,76 & 0,76 & 0,68 & 0,68 & 0,66 & 0,66 \\
\hline Cloro (\%) & 0,35 & 0,35 & 0,34 & 0,34 & 0,32 & 0,32 & 0,31 & 0,31 & 0,31 & 0,31 \\
\hline Acido linoléico (\%) & 2,48 & 2,35 & 2,21 & 2,11 & 2,56 & 2,43 & 2,53 & 2,40 & 2,77 & 2,68 \\
\hline EMA (kcal/kg) & 2920 & 2920 & 2980 & 2980 & 3050 & 3050 & 3100 & 3100 & 3150 & 3150 \\
\hline PB (\%) & 22,0 & 22,0 & 20,0 & 20,0 & 19,0 & 19,0 & 17,80 & 17,80 & 17,00 & 17,00 \\
\hline Cálcio (\%) & 0,92 & 0,92 & 0,86 & 0,86 & 0,75 & 0,75 & 0,65 & 0,65 & 0,58 & 0,58 \\
\hline P disponível (\%) & 0,47 & 0,47 & 0,38 & 0,38 & 0,33 & 0,33 & 0,29 & 0,29 & 0,26 & 0,26 \\
\hline Metionina dig. (\%) & 0,64 & 0,64 & 0,54 & 0,55 & 0,49 & 0,49 & 0,45 & 0,45 & 0,41 & 0,41 \\
\hline Met.+cis dig. (\%) & 0,94 & 0,94 & 0,82 & 0,82 & 0,75 & 0,75 & 0,70 & 0,70 & 0,65 & 0,65 \\
\hline Lisina dig. (\%) & 1,30 & 1,30 & 1,14 & 1,14 & 1,04 & 1,04 & 0,96 & 0,96 & 0,89 & 0,89 \\
\hline Sódio (\%) & 0,22 & 0,22 & 0,21 & 0,21 & 0,20 & 0,20 & 0,19 & 0,19 & 0,19 & 0,19 \\
\hline \multicolumn{11}{|c|}{ 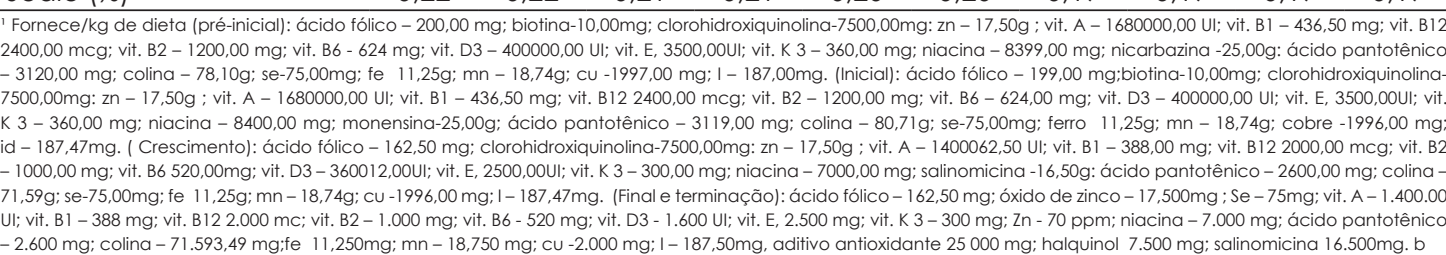 } \\
\hline
\end{tabular}

O programa nutricional utilizado durante o experimento foi composto por cinco rações, destinadas às diferentes fases de criação das aves: pré-inicial de um a sete dias, inicial de oito a vinte e um dias, crescimento de vinte $e$ dois a trinta e cinco dias, final de trinta e seis a quarenta e dois dias e terminação de quarenta e três a quarenta e seis dias. O manejo diário incluiu lavagem de bebedouros, fornecimento de água, fornecimento de ração e verificação da mortalidade. A água e a ração foram fornecidas à vontade para os animais durante todo o período experimental.

A avaliação de desempenho foi realizada por meio de pesagem das aves e da ração no início e no final de cada fase. Foi avaliado o consumo de ração, ganho de peso e conversão alimentar desses animais no período de 1 a 46 dias.

Os animais foram eutanasiados aos 46 dias de idade conforme resolução 1000/2012 do Conselho Federal de Medicina Veterinária (CFMV, 2012) e todo o procedimento utilizado na condução do experimento foi submetido ao Comitê de Ética Animal da Universidade Federal do Piauí e aprovado sob parecer n89/12.

Realizou-se a contenção manual das aves, seguida de limpeza da face medial da asa e antissepsia; anestesia local na região, procedeu-se a aplicação de um cordão 
anestésico de lidocaína sem vasoconstritor na dose de $5 \mathrm{mg} / \mathrm{kg}$ por via subcutânea (Viana, 2014) com o intuito de dessensibilizar a região para realizar a punção da veia radial.

Após anestesia local, foi feita a dissecação da veia radial e isolamento da mesma com auxílio de fios de sutura e canulação do vaso, seguido da injeção de heparina na dose de 150Ul/Kg PV, depois de transcorridos dois minutos, administrou-se tiopental na dose de $15 \mathrm{mg} / \mathrm{Kg}$ PV, pela mesma via (Viana, 2014).

Com o óbito devidamente constatado fez-se a perfusão de formaldeído tamponado a $10 \%$ por gravidade, durante 6 horas (média $780 \mathrm{ml} /$ animal), seguido de imersão em cuba contendo mesma solução, por no mínimo 72 horas (Chen, 2010).

Após este período os animais foram dissecados com auxílio de pinças anatômicas, bisturi e de lupa de Pala, que proporcionou melhor visualização dos órgãos. Os dados da mensuração macroscópica dos órgãos foram obtidos com paquímetro digital e fita métrica. Ao término das mensurações de cada indivíduo, o tubo digestório foi segmentado a partir da realização de cortes transversais, em fragmentos de aproximadamente $0,125 \mathrm{~cm}^{3}$ e esses fragmentos armazenados em cassetes histológicos, onde permaneceram imersos em solução de formaldeído a 10\% (Rodrigues, 1998), até o processamento histológico.

Com o material devidamente coletado, iniciou-se o processamento histológico padrão com inclusão em Paraplast ${ }^{\circledR}$ (Paraplast Embedding Media - Paraplast Plus ${ }^{\circledR}$ ) e posterior secção dos blocos na espessura de $4 \mu \mathrm{m}$ em micrótomo rotativo semiautomático. Os cortes foram corados em Hematoxilina-Eosina (HE) (Xia et al., 2004, Hu et al., 2012).

Foram realizadas duas analises: análise semi-quantitativa das alterações histopatológicas, a partir do estudo microscópico e a macroscópica, para mensuração do comprimento dos órgãos do tubo digestório e análise quantitativa para avaliação do desempenho.

As alterações histopatológicas foram analisadas pelo método semi-quantitativo, que classifica as alterações quanto ao grau de intensidade das lesões, numa escala de 0 a 5 em que 0 = normal, 1 = leve, 2 = levemente moderada, 3 = moderada, 4 = moderadamente severa, 5 = severa (Pirani, 1994).

A avaliação semi-quantitativa foi realizada pela análise dos cortes em microscópio biológico, este avaliou a presença e a intensidade das alterações histopatológicas, as observações foram foto micrografadas por meio de ocular digital de dois megapixels (DEM200 Digital Eyepiece for Microscope - Scopetek ${ }^{\circledR}$ ) acoplada a um microscópio biológico trilocular $\left(\mathrm{Nova}^{\circledR}\right)$, associada ao software de captura Minisee ${ }^{\circledR}$.

Os resultados da avalição semiquantitativa foram analisados no programa estatístico Bioestat 5.3 ${ }^{\circledR}$ (Ayres et al., 2007), por testes não-paramétrico: a) método de MannWhitney para comparação entre dois grupos, b) método de Kruskal-Wallis para análise de variância. Havendo diferença significante aplicava-se o teste de Student-Newman-Keuls para comparação múltipla de grupos. Adotouse o nível de significância de p>0,05; a avaliação quantitativa dos dados de desempenho foram analisadas no mesmo programa aplicandose o teste de Student-Newman-Keuls para comparação múltipla de grupos.

No estudo macroscópico foram avaliados: peso vivo do animal, comprimento total e diâmetro do esôfago (mensurado da laringe até sua junção com o pro ventrículo), inglúvio, pro ventrículo, ventrículo, intestino delgado (duodeno: a partir do piloro até a porção distal da alça duodenal; jejuno: a partir da alça duodenal distal até a junção ileocecal; e o íleo: da porção anterior dos cecos até a junção ileocecal) e intestino grosso (cecos: das suas bases até o ápice e o colón: da junção ileocecal até porção anterior da coacla), regiões definidas segundo Guetty (1986). O diâmetro dos órgãos foi aferido nas porções proximal, média e distal.

As mensurações de comprimento e diâmetro foram avaliadas através de análise estatística descritiva, realizada com mesmo software. 


\section{Resultados}

Ao realizar a análise histológica foi possível observar dois tipos de alterações histopatológicas: infiltrados inflamatórios e congestão. Sendo que, nesta análise somente foram considerados os infiltrados inflamatórios, pois a congestão apresentada pode ser considerada iatrogênica, devido à técnica de fixação utilizada, e por se apresentar de maneira semelhante nos dois grupos.

Visualizou-se alterações histopatológicas em ambos os grupos (controle e teste), porém os que não receberam glicerina na dieta apresentaram-na em menor grau de intensidade, exceto na porção do duodeno, em que dois animais do grupo controle exibiram alterações, um foi classificado como grau 1 (leve) e o outro grau 2 (levemente moderada), mas sem diferença significativa (Tabela 03), já no grupo teste todos exibiram grau igual a zero, considerado normal (sem alterações), nesse segmento do intestino delgado.

Tabela 3. Comparação da frequência (\%) e intensidade dos infiltrados inflamatórios em diferentes órgãos do tubo digestório de frangos da linhagem Cobb $500^{\circledR}$ alimentados com dieta controle (C) e com dieta contendo $7 \%$ de glicerol (T).

\begin{tabular}{|c|c|c|c|c|c|c|c|c|c|c|c|c|}
\hline & \multicolumn{12}{|c|}{ Grau de intensidade (\%) } \\
\hline & \multicolumn{2}{|c|}{ Normal } & \multicolumn{2}{|c|}{ Leve } & \multicolumn{2}{|c|}{$\begin{array}{l}\text { Levemente } \\
\text { moderada }\end{array}$} & \multicolumn{2}{|c|}{ Moderada } & \multicolumn{2}{|c|}{ Mod. Severa } & \multicolumn{2}{|c|}{ Severa } \\
\hline & C & $T$ & C & $\mathrm{T}$ & $\mathrm{C}$ & $\mathrm{T}$ & $\mathrm{C}$ & $T$ & C & $\mathrm{T}$ & $\mathrm{C}$ & $T$ \\
\hline Esôfago & 100 & 50 & 0 & 25 & 0 & 25 & 0 & 0 & 0 & 0 & 0 & 0 \\
\hline Inglúvio & 75 & 50 & 25 & 12,5 & 0 & 25 & 0 & 12,5 & 0 & 0 & 0 & 0 \\
\hline Proventrículo & 62,5 & 12,5 & 37,5 & 37,5 & 0 & 37,5 & 0 & 12,5 & 0 & 0 & 0 & 0 \\
\hline Ventrículo & 100 & 100 & 0 & 0 & 0 & 0 & 0 & 0 & 0 & 0 & 0 & 0 \\
\hline Duodeno & 75 & 100 & 12,5 & 0 & 12,5 & 0 & 0 & 0 & 0 & 0 & 0 & 0 \\
\hline Jejuno & 62,5 & 75 & 37,5 & 0 & 0 & 25 & 0 & 0 & 0 & 0 & 0 & 0 \\
\hline Íleo & 37,5 & 50 & 50,0 & 37,5 & 12,5 & 12,5 & 0 & 0 & 0 & 0 & 0 & 0 \\
\hline Ceco D & 50 & 25 & 12,5 & 12,5 & 37,5 & 25 & 0 & 12,5 & 0 & 25 & 0 & \\
\hline Ceco E & 62,5 & 25 & 12,5 & 0 & 25 & 0 & 0 & 37,5 & 0 & 25 & 0 & 12,5 \\
\hline Cólon & 75 & 12,5 & 12,5 & 37,5 & 12,5 & 25 & 0 & 25 & 0 & 0 & 0 & 0 \\
\hline
\end{tabular}

Dentre os órgãos avaliados no grupo controle, não foram visualizados nenhum tipo de infiltrado inflamatório no esôfago e no ventrículo, considerando assim o tecido normal. No grupo tratado, também foi considerado normal no ventrículo e no duodeno. Os demais segmentos do tubo digestório exibiram algum grau de inflamação (presença de infiltrado inflamatório), em ambos os grupos (controle e teste).

Ao realizar a análise estatística de todas as observações, comparando os diferentes graus de intensidade das alterações, constatouse diferença significativa nos animais que receberam adição de $7 \%$ de glicerina na dieta, nos seguintes órgãos: pro ventrículo, ceco direito, ceco esquerdo e cólon ( $p>0,05$, Teste de Kruskal Wallis e Student-Newman-Keuls).

Foram avaliados os 8 animais que receberam dieta contendo glicerina, dos quais $7(87,5 \%)$ apresentaram infiltrado inflamatório no pro ventrículo. Tanto no ceco direito como no ceco esquerdo 6 animais (75\%) demonstraram a alteração, já no cólon observou-se alterações em 7 animais (87,5\%). Os percentuais dos diferentes graus de alterações nos órgãos do tubo digestório dos animais que ingeriram dieta controle e dos que ingeriram dieta contendo glicerina estão descritos de forma comparativa na tabela 3.

Um comparativo da intensidade dos infiltrados inflamatórios nos animais que receberam glicerina na dieta em relação aos que não receberam esta apresentadado na figura 1, lembrando que a analise foi realizada em todo o corte históológico e que esta figura representa apenas uma área da lamina como demonstração do tipo e intesidade da lesão observados em cada orgão.

No estudo macroscópico do peso ao abate e comprimento dos órgãos do tubo digestório, não houve diferença estatística entre os grupos, estando descrita esses valores na tabela 4. Sendo assim podemos afirmar que a glicera quando adicionada a $7 \%$ da dieta não causa alterações no comprimento do trato digestório nem no peso dos animais 

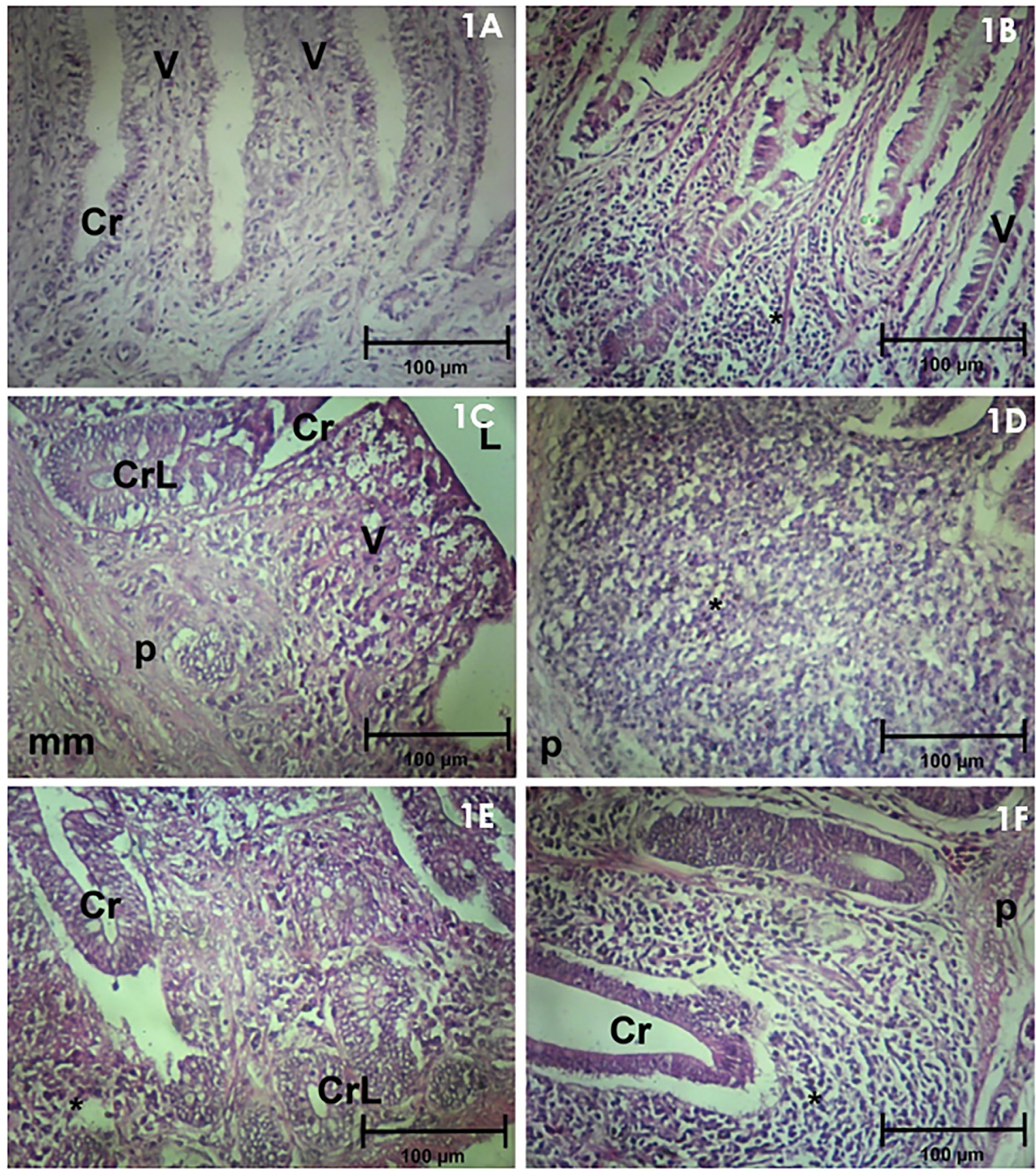

Figura 1. Fotomicrografia de infiltrados inflamatórios no tubo digestório de frangos. 1A: proventrículo de frango alimentado com dieta controle. $\mathrm{V}=$ vilos. $\mathrm{Cr}=$ cripta. $1 \mathrm{~B}$ : proventrículo de frango que alimentado com dieta contendo glicerina. $\mathrm{V}=\mathrm{vil}$ ilos. ${ }^{*}=$ infiltrado inflamatório. 1C: ceco de frango que alimentado com dieta controle. $\mathrm{V}=\mathrm{vilo}$. $\mathrm{Cr}=\mathrm{cripta}$. $\mathrm{CrL}=\mathrm{cripta}$ de Linberking. $\mathrm{p}=$ lâmina

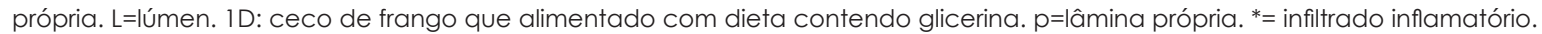
IE: cólon de frango alimentado com dieta controle. $\mathrm{Cr}=\mathrm{cripta}$. $\mathrm{CrL}=$ cripta de Linberking. IF: cólon de frango alimentado com dieta contendo glicerina. $\mathrm{Cr}=$ cripta $^{*}=$ infiltrado inflamatório. $\mathrm{p}=$ =lâmina própria 
Tabela 4. Estatística descritiva do peso e comprimento de órgãos do tubo digestório de frangos da linhagem Cobb $500^{\circledR}$ alimentados com dieta controle (C) em com dieta contendo $7 \%$ de glicerol (T)

\begin{tabular}{|c|c|c|c|c|c|c|c|c|c|c|c|c|}
\hline & \multicolumn{2}{|c|}{ Mínimo } & \multicolumn{2}{|c|}{ Máximo } & \multicolumn{2}{|c|}{$\begin{array}{c}\text { Amplitude } \\
\text { Total }\end{array}$} & \multicolumn{2}{|c|}{ Média Aritmética } & \multicolumn{2}{|c|}{ Desvio Padrão } & \multicolumn{2}{|c|}{$\begin{array}{l}\text { Coeficiente de } \\
\text { Variação (\%) }\end{array}$} \\
\hline & C & $\mathrm{T}$ & C & $\mathrm{T}$ & C & $\mathrm{T}$ & C & $\mathrm{T}$ & C & $\mathrm{T}$ & $C$ & $\mathrm{~T}$ \\
\hline Peso (g) & 2416 & 2338 & 3038 & 3040 & 622 & 702 & 2733,75 & 2706,75 & 214,37 & 237,19 & $7,84 \%$ & $8,76 \%$ \\
\hline Esôfago (cm) & 14 & 13 & 19 & 19 & 5 & 6 & 15,50 & 15,88 & 1,51 & 2,03 & $9,75 \%$ & $12,79 \%$ \\
\hline Inglúvio (cm) & 4 & 3 & 6 & 8 & 2 & 5 & 4,88 & 5 & 0,99 & 1,41 & $20,33 \%$ & $28,28 \%$ \\
\hline Proventr. (cm) & 5 & 5 & 7 & 6,5 & 2 & 1,5 & 5,38 & 5,31 & 0,74 & 0,59 & $13,84 \%$ & $11,18 \%$ \\
\hline Ventrículo (cm) & 7 & 7 & 11 & 10 & 4 & 3 & 8,50 & 8,38 & 1,20 & 0,92 & $14,06 \%$ & $10,94 \%$ \\
\hline Duodeno $(\mathrm{cm})$ & 27 & 27 & 39 & 58 & 12 & 31 & 32,38 & 36,38 & 4,24 & 9,80 & $13,10 \%$ & $26,93 \%$ \\
\hline Jejuno (cm) & 101 & 76 & 124 & 146 & 23 & 70 & 110,88 & 110,63 & 9,39 & 21,80 & $8,47 \%$ & $19,70 \%$ \\
\hline Íleo (cm) & 16 & 15 & 25 & 26 & 9 & 11 & 20,25 & 18,50 & 3,20 & 3,34 & $15,78 \%$ & $18,04 \%$ \\
\hline Ceco E (cm) & 19 & 17 & 24 & 23 & 5 & 6 & 21,38 & 20,34 & 1,92 & 2,21 & $8,99 \%$ & $10,87 \%$ \\
\hline Ceco D (cm) & 19 & 18 & 22 & 23 & 3 & 5 & 20,75 & 21,13 & 1,17 & 1,96 & $5,61 \%$ & $9,28 \%$ \\
\hline Cólon (cm) & 6 & 6 & 9 & 9 & 3 & 3 & 7,875 & 7,75 & 0,99 & 1,04 & $12,58 \%$ & $13,36 \%$ \\
\hline
\end{tabular}

Na avaliação do desempenho do peso médio, ganho de peso, conversão alimentar e consumo de ração, também não encontramos diferença estatística entre os tratamentos como mostra a tabela 5 e 6. Fato esse que nos permiteiu concluir que não a vantagens aparentes para a inclusão deste componente na dieta.

Tabela 5. Média de ganho de peso de frangos da linhagem Cobb 500 ${ }^{\circledR}$ alimentados com dieta controle (C) em com dieta contendo $7 \%$ de glicerol (T) corte aos 46 dias de idade

\begin{tabular}{c|c|c|c}
\hline Tratamento & Peso médio inicial & Peso Médio Final & GP \\
\hline$C$ & $39,56 a$ & $2492,50^{a}$ & $2453,30^{*}$ \\
\hline * teste de médias (Student) com resultado não significativo. GP=ganho de peso.
\end{tabular}

Tabela 6. Conversão Alimentar de frangos da linhagem Cobb $500^{\circledR}$ alimentados com dieta controle (C) em com dieta contendo $7 \%$ de glicerol (T) corte aos 46 dias de idade

\begin{tabular}{|c|c|c|c|}
\hline Tratamento & CRM & GP & $\mathrm{CA}$ \\
\hline $\mathrm{C}$ & 6036,42 & 2453,30 & $2,46^{*}$ \\
\hline$T$ & 6566,72 & 2468,17 & $2,66^{*}$ \\
\hline
\end{tabular}

\section{Discussão}

O sistema imune do trato gastrointestinal encontra-se constantemente exposto a patógenos, a agentes físicos e químicos oriundos principalmente dos alimentos, tais fatores podem interferir na homeostase do sistema digestório e o organismo pode desenvolver uma resposta inflamatória. Para Gregor \& Hotamisligil (2011) a resposta inflamatória induzida pela dieta, é desencadeada pelo fato de que os nutrientes por si só já sejam naturalmente inflamatórios, ou seja, exista resposta fisiológica das células metabólicas frente aos nutrientes o que resulta na ocorrência da inflamação de baixa intensidade. Diante do exposto, podemos compreender a presença de infiltrados inflamatórios no decorrer do tubo digestório, tanto dos animais que receberam dieta controle (sem glicerina) como naqueles que ingeriram dieta contendo glicerina. No entanto, a resposta inflamatória não deve ser considerada maléfica quando é controlada, pois é uma resposta com finalidade fisiológica e pode ter o papel de proteção contra algum patógeno e demonstra o objetivo de restauração da homeostase e a adaptação a este estresse (Medzhitov, 2008). Em um experimento com peixes submetidos a diferentes ambientes e a dietas com e sem adição de probioticos os autores demonstram que o ambiente tem, maior inlfluencia que o uso de probioticos (Ferreira et al., 2016), e este fato remete a situação de nosso trabalho que apesar de ter sido utilizado um adtivo na dieta este não foi o responsável pela alteração, sugerindo que o processo inflamatório teve sua origem no ambiente. 
O acesso livre a nutrientes favorece a ingestão excessiva de energia, podendo culminar com a hiperalimentação e associado ao limitado gasto energético, resultaria em desequilíbrio oxidativo e imunológico, o que favorece a ocorrência de disfunção celular e consequentemente doenças metabólicas (Burton \& Freeman 2010), vale ressaltar que tais animais receberam alimentação ad libium, durante todo o experimento, além de pertencerem a uma linhagem comercial de frangos (Cobb 500 ${ }^{\circledR}$ ) e essa apresenta o comportamento de hiperfagia, característica imprimida pelo melhoramento genético (Bertechini et al., 1991; Bartov \& Plavnik, 1998; Silva et al., 2003), esses fatores também podem ter influenciado a ocorrência das alterações apresentadas (infiltrados inflamatórios) no tubo digestório nos dois grupos (Controle e Teste) dos animais do experimento.

As alterações histopatológicas foram significativas no pro ventrículo, levando em consideração que este órgão é o estômago químico das aves e que a mucosa gástrica ao ser exposta a ação de algum produto com função álcool pode sofrer reações como disfunção da barreira secretora muco-protetora, o que leva um aumento da secreção de íons $\mathrm{H}^{+}$na mucosa estomacal e em consequência pode gerar úlceras, infiltração de células inflamatórias e desordens de motilidade (Siegmund, Teyssen \& Singer, 2002; Jahovic et al., 2007; Matsuhashi et al., 2007), esclarecendo a presença de diferença significativa em relação ao grau de infiltrado inflamatório no pro ventrículo dos animais que receberam dieta contendo glicerina, devido este ingrediente possuir metanol em sua composição, como demonstrado na tabela 01.

O intestino possui sistema imune capaz de diferenciar entre dois tipos de materiais estranhos: antígenos inofensivos, tais como proteínas alimentares e bactérias comensais do intestino precisam ser tolerados, enquanto que antígenos provenientes de patógenos precisam acionar a resposta imune, porém há diferença entre resposta e tolerância (Mowat, 2003; Beal et al., 2006). Os sinais de uma resposta imunológica em curso no intestino incluem o aumento da infiltração de leucócitos na lâmina própria e as mudanças na estrutura do intestino, como a atrofia das vilosidades e hiperplasia dos enterócitos nas criptas (Beal et al., 2006; Smith \& Beal, 2008). Os componentes do sistema imunológico das aves são: a Bursa de Fabricius, infiltrados linfoides difusos na mucosa dos intestinos, tonsilas cecais, divertículo de Meckel e placas de Peyer (Christensen et al., 2006; Smith \& Beal, 2008). O intestino delgado possui tecido linfoide pouco organizado, quando comparado com o do intestino grosso (Befus et al., 1980), considerando a maior quantidade de tecido linfático nessa porção do tubo digestório e que no intestino grosso também ocorre reabsorção de líquidos, Segundo a União Internacional da Química Pura e Aplicada IUPAC (1993) a glicerina possui característica higroscópica e baixo peso molecular, possuindo absorção passiva, justifica-se a presença de resposta inflamatória significativa nessa porção, pois a glicerina pode estar agendo de forma competitiva com os líquidos, pelo fato dessa reter líquido (característica higroscópica).

\section{Conclusão}

Concluímos que o uso da glicerina na dieta ocasiona processos inflamatórios localizados, aqual se apresenta com intensidade mais elevada intestino grosso (cecos e cólon). Contudo as alterações encontradas não influenciaram o desempenho zootécnico dos experimentas.

\section{Referências}

Arruda, P.V.; Rodrigues, R.C.L.B.; Felipe, M.G.A. 2007. Glicerol: um subproduto com grande capacidade industrial e metabólica. Revista Analytica. 26.

Ayres M., Ayres Júnior M., Ayres D.L., Santos A.A. 2007. BIOESTAT - Aplicações estatísticas nas áreas das ciências bio-médicas. Ong Mamirava. Belém, PA.

Bartov I, Plavnik I. 1998. Moderate excess of dietary protein increases breast meat yield of broilers chicks. Poultry Science, 77, 680-688.

Batista, E., Furlan, A.C., Ton, A.P.S., Pasquetti, T.J., Quadros, T.C.O., Grieser, D.O., Zancanela, V. 2013. Avaliação nutricional da glicerina vegetal semipurificada para codornas de corte. Arquivo Brasileiro de Medicina Veterinária e Zootecnia, 36(6):1783-1791. 
Beal R.K., Powers C., Davison T.F., Smith A.L. 2006. Immunological development of the avian gut in: Perry G.C. Avian Gut Function in Health and Disease, Cab International, Wallingford. v. 28, cap. 6, p. 85-103.

Befus A.D., Johnston N., Leslie G.A., Bienenstock J. 1980. Gut-associated lymphoid tissue in the chicken. I. Morphology, ontogeny and some functional characteristics of Peyer's patches, Journal of immunology 125(6), p. 2626-2632.

Bertechini AG, Rostagno HS, Soares PR, Oliveira AIG. 1991. Efeitos de programas de alimentação e níveis de energia da ração sobre o desempenho e a carcaça de frangos de corte. Revista Brasileira de Zootecnia 20(3), 267-280.

Burton e Freeman, B. 2010. Postprandial metabolic events and fruit-derived phenolics: a review of the science. British Journal of Nutrition 104, p.S1-S14.

Cerrate, S.; Yan, F.; Wang, Z. 2006. Evaluation of glycerine from biodiesel production as a feed ingredient for broilers. International Journal of Poultry Science 5(11), p. 1001-1007.

Chen S. et al. 2010. Histopathology, immunohistochemistry, in situ apoptosis, and ultrastructure characterization of the digestive and lymphoid organs of new type gosling viral enteritis virus experimentally infected gosling. Poultry Science 89, 668-680.

Christensen J.P., Chadfield M.S., Olsen J.E., Bisgaard M. 006. The gastrointestinal tract as a port of entry for bacterial infections in poultryin: Perry,G.C. Avian Gut Function in Health and Disease, Cab International, Wallingford, 2v. 28, cap. 16, p. 244-258.

Ferreira, A.H.C., Lopes, J.B., Araripe, M.N.B.A., Monteiro, C.A.B., Andrade, F.T., Kimpara, J.M., 2016. Probiótico na alimentação de tilápias cultivadas em efluentes de esgotos doméstico tratado. Comunicata Scientiae 7(2), p. 262-271.

Getty, R. 1986. Anatomia dos animais domésticos, Rio de Janeiro, 5ed. Interamericana, v.2.

Gregor, M.F. Hotamisligil, G.S. 2011 .Inflammatory Mechanisms in Obesity. Annual Review of Immunology 29, p.415-445, .

Guerra, R.L.H. Murakami, A.E. Garcia, A.F.Q.M. Urgnani, F.J. Moreira, I. Picoli. K.P. 2011. Glicerina bruta mista na alimentação de frangos de corte (1 a 42 dias). Revista Brasileira Saúde e Produção Animal 12, p.1038-1050.

HU C. H. et al. 2012. Effects of montmorillonite-zinc oxide hybrid on performance, diarrhea, intestinal permeability and morphology of weanling pigs. Animal Feed Science Technology 177, p. 108-
115.

IUPAC, Nomenclatura de Compostos Orgânicos, Recomendações 1993, Publicações Científicas Blackwell. Editado por R Panico, WH Powell e Richer JC. [ISBN 0-632-03488-2].

Jahovic N., Erkanli G., Iseri S., Arbak S., Alican I. 2007. Gastric protection by a-melanocytestimulating hormone against ethanol in rats: Involvement of somatostatina. Life Sciences 80, p. $1040-1045$.

Mandalawi, H.A., Kimiaeitalab, M.V., Obregon, V., Menoyo, D., Mateos, G.G. 2017. Influence of source and level of glycerin in the diet on growth performance, liver characteristics, and nutrient digestibility in broilers from hatching to 21 days of age. Poultry Science 93, p. 2855-2863.

Matsuhashi, T., Otaka, M., Odashima, M., Jin, M., Komatsu, K., Wada, I., Horikawa, Y., Ohba, R., Oyake, J., Hatakeyama, N., Watanabe, S. 2007. Protective effect of a novel rice extract against ethanol-inducedgastric mucosal injury in rat. Digestive Diseases and Sciences 52, p. $434-441$.

Medzhitov, R., 2008. Origin and physiological roles of inflammation. Nature 454, p.428-435.

Mowat A.M., 2003. Anatomical basis of tolerance and immunity to intestinal antigens. Nature Reviews Immunology 3(4), p. 331-341.

Pirani C.L. 1994. Evaluation of kidney biopsy specimens. In: Tisher C.C., Brenner, B.M. Renal Pathology: with clinical and functional correlations. 2. ed. Philadelphia: J.B. Lippincott Company. 2 vol. p. 85-115.

Rodrigues H. 1998. Técnicas anatômicas. Vitória: Arte Visual. $222 \mathrm{p}$.

Rostagno et al. 2011 . Tabelas brasileiras para aves e suínos: composição de alimentos e exigências nutricionais. $3^{a}$ ed. Viçosa, MG: Universidade Federal de Viçosa, $252 \mathrm{p}$

Santos E.T. 2013. Glicerina como estratégia nutricional para frangos de corte criados em região de clima quente. Dissertação (Mestre em Zootecnia). Departamento de Zootecnia, Universidade Federal do Piauí, Bom Jesus, Brasil

Siegmund, Teyssen \& Singer. 2002. Alcoholassociated organ demage. Health sequelae caused by moderate alcohol drinking. Internist 43, p. 287-293.

Silva J.H.V., Albino L.F.T., Nascimento A.H. 2003. Estimativas da composição anatômica da carcaça de frangos de corte com base no nível de proteína da ração e peso da carcaça. Revista Brasileira de Zootecnia 32(2), 344-352. 
Smith A.L., Beal R. 2008. The avian enteric immune system in health and disease. In: Davison, F.; Kaspers, B.; Schat, K.A. Avian Immunology. Academic Press, London, cap. 13, p. 243-271.

Sousa, C. D. Oliveira, N.L.A., Dourado, L.R.B., Ferreira, G.J. 2015a. Sistema digestório das aves e o glicerol na dieta de frangos de corte: Revisão. PUBVET 9(8), p. 369-380, 2013.

Sousa, D.C., Oliveira, N.L.A., Santos, E.T., Guzzi, A., Dourado, L.R.B., Ferreira, G.J. 2015b. Caracterização morfológica do trato gastrointestinal de frangos de corte da linhagem Cobb $500 \AA$. Pesquisa Veterinária Brasileira 35(Supl. 1):61-68.

Viana F. A. B. 2014. Guia terapêutico Veterinário. $3^{a}$ edição. Lagoa Santa: Gráfica e Editora CEM.

XIA M. S.; HU C. H.; XU Z. R. Effects of copper bearing montmorillonite on growth performance, digestive enzyme activities, intestinal microflora and morphology of male broilers. Poultry Science 83, p. 1868-1875, 2004. 